Journal of Health Science
(Jurnal Ilmu Kesehatan)
$\frac{\mathrm{https} / / / \text { www.ejournalwiraraja.com/index.php/JIK }}{2356-5284 \text { (Print) } \mid 2356-5543 \text { (online) }}$

\title{
Peran Petugas Kesehatan dan Keluarga terhadap Self Care Penderita Kusta
}

\author{
Mujib Hannan ${ }^{1}$, Syaifurrahman Hidayat ${ }^{2}$, Mayank Nirmala Sandi ${ }^{3}$
}

1,2,3Program Studi Keperawatan Fakultas Ilmu Kesehatan, Universitas Wiraraja

미jib@wiraraja.ac.id ${ }_{2}^{2}$ dayat.fik@wiraraja.ac.id, ${ }^{3}$ nirmalasandimayank@gmail.com

* corresponding author

\begin{tabular}{l} 
Informasi artikel \\
Received: 06-10-2020 \\
Revised: 16-112020 \\
Accepted: $26-11-2020$ \\
\hline
\end{tabular}

\section{Kata kunci:}

Kusta

Peran Petugas Kesehatan

Peran Keluarga

Self Care

\begin{abstract}
ABSTRAK
Penyakit menular yang masih ditemukan pada masyarakat Indonesia yaitu kusta, Indonesia menduduki peringkat ketiga di dunia setelah brazil. Jawa Timur berada pada peringkat pertama dengan jumlah kasus baru kusta terbanyak pada tahun 2018 yaitu dengan jumlah 2.701 jiwa. Self care individu dipengaruhi usia, jenis kelamin, status perkembangan, status kesehatan, sosiokultural, pelayanan kesehatan, sistem keluarga, pola hidup, lingkungan, dan ketersediaan sumber. Tujuan penelitian ini untuk mengetahui peran petugas kesehatan dan keluarga terhadap self care penderita kusta di Kecamatan Batuputih Kabupaten Sumenep. Desain penelitian analitik dengan rancang bangun Cross Sectional. Populasi yaitu penderita kusta di Puskesmas Batuputih. Teknik sampling purposive sampling dengan sampel sebanyak 32 responden. Uji Statistik menggunakan uji korelasi spearman. Hasil penelitian dari 25 responden diperoleh sebagian besar petugas kesehatan ikut berperan dalam self care penderita kusta sebanyak 16 orang (64,0\%), sebagian besar keluarga tidak berperan dalam self care penderita kusta sebanyak 15 orang (60,0\%), hampir seluruhnya self care dalam kategori kurang sebanyak 20 orang $(80,0 \%)$, tidak ada hubungan peran petugas kesehatan terhadap self care penderita kusta dengan Sig. 0,065 $(>0,05)$ dan ada hubungan peran keluarga terhadap self care penderita kusta dengan Sig. 0,001 $(<, 0,05)$ di Kecamatan Batuputih Sumenep dengan hasil uji Spearman's. Keluarga yang tidak berperan menyebabkan self care yang buruk bagi penderita kusta sehingga hal ini dapat meningkatkan risiko kecacatan dan memperparah kondisi penderita kusta. Peran petugas kesehatan dan keluarga yang aktif dalam mendukung self care penderita kusta dapat mempermudah proses penyembuhan dan pemulihan penderita kusta serta sebagai langkah menekan angka penyebaran penyakit kusta.
\end{abstract}

Key word: Leprosy

Role of Health Workers Family Role Self Care

\begin{abstract}
An infectious disease that is still found in Indonesian society, namely leprosy, Indonesia ranks third in the world after Brazil. East Java is in the first place with the highest number of new cases of leprosy in 2018, with 2,701 people. Individual self care is influenced by age, gender, developmental status, health status, socio-culture, health services, family system, lifestyle, environment, and availability of resources. The purpose of this study was to determine the role of health workers and families in self-care for people with leprosy in Batuputih District, Sumenep Regency. Analytical research design with cross sectional design. The population is people with leprosy in Batuputih Health Center. The sampling technique was purposive sampling with a sample of 32 respondents. Statistical test using the Spearman correlation test. The results of the study of 25 respondents obtained that most of the health workers participated in the self-care of leprosy sufferers as many as 16 people (64.0\%), most of the families did not play a role in self-care for people with leprosy as many as 15 people $(60.0 \%)$, almost all of them were self-care. care in the less category as many as 20 people $(80.0 \%)$, there is no relationship between the role of health workers and self-care for people with leprosy with Sig.
\end{abstract}


0.065 (> 0.05) and there is a relationship between family roles and selfcare for lepers with Sig. $0.001(<0.05)$ in Batuputih Sumenep District with the results of the Spearman test. Families who do not play a role cause bad self-care for people with leprosy so that this can increase the risk of disability and worsen the condition of lepers. The role of health workers and families who are active in supporting self-care for people with leprosy can facilitate the healing and recovery process for people with leprosy and as a step to reduce the spread of leprosy.

\section{Pendahuluan}

$\begin{array}{lll}\text { Berakhirnya } & \text { Millennium Development } \\ \text { Goals para pemimpin dunia }\end{array}$ mengembangkan konsep pembangunan global yang dikenal dengan Sustainable Development Goals (Sutopo, Arthati, \& Rahmi, 2014). Tujuan pembangunan berkelanjutan (TPB) ini memiliki 17 tujuan, diantaranya yaitu kehidupan sehat dan sejahtera (Badan Pusat Statistik, 2018). Kehidupan sehat dan sejahtera di Indonesia masih terus dikembangkan, salah satu hambatannya yaitu kejadian penyakit menular yang masih tinggi. Penyakit menular yang masih ditemukan pada masyarakat Indonesia yaitu kusta. Agen penyebab kusta atau lepra ditemukan oleh ilmuwan dari Norwegia yang bernama Gerhard Henrik Armauer Hansen pada 28 Februari 1873 sehingga kusta juga disebut Morbus Hansen (Amiruddin, 2019).

Indonesia berada pada peringkat ketiga di dunia dengan penemuan kasus baru kusta terbanyak yaitu 17.202 jiwa pada tahun 2015 setelah brazil. Indonesia belum bisa dinyatakan bebas dari kusta karena prevalensi dan penemuan kasus baru kusta masih mengalami peningkatan. Selama periode 2015-2016 provinsi Jawa Timur termasuk angka beban kusta tinggi (Pusdatin Kemenkes RI, 2018). Jawa Timur berada pada peringkat pertama dengan jumlah kasus baru kusta terbanyak pada tahun 2018 yaitu dengan jumlah 2.701 jiwa (Pusdatin Kemenkes RI, 2019). Kabupaten Sumenep yang terletak di Provinsi Jawa Timur tergolong tinggi penemuan kasus baru kusta yaitu 327 jiwa, baik penderita kusta tipe pausi basiler (PB) maupun multi basiler (MB) dengan menduduki peringkat ketiga setelah Kabupaten Pamekasan pada tahun 2019 (Dinas Kesehatan Provinsi Jawa Timur, 2020). Sebanyak 30 puskesmas yang berada di Kabupaten Sumenep terdapat kasus kusta dari jumlah terendah hingga tertinggi. Puskesmas Batuputih menduduki peringkat kedua penderita baru dengan total 35 jiwa setelah puskesmas Gayam dengan total 42 jiwa pada tahun 2019 (Dinas Kesehatan Kabupaten Sumenep, 2020).

Studi pendahuluan yang dilakukan pada bulan Februari 2020 dengan cara wawancara langsung dengan penderita kusta di dua desa yaitu 7 orang di Desa Gedang-Gedang dan 9 orang di Desa Badur Kecamatan Batuputih Kabupaten Sumenep. Ditemukan sebanyak 14 orang atau $87,5 \%$ penderita kusta mengatakan kurang paham mengenai kusta dan cara melakukan self care dan 2 orang atau 12,5\% lainnya cukup bisa melakukan self care.

Perawatan diri yang buruk pada penderita kusta dapat menimbulkan kerusakan yang progresif karena kusta menyerang saraf tepi, kulit, tangan dan kaki serta mata, maka penderita memerlukan self care yang baik (Infodatin, 2018). Orem (2001) menyebutkan bahwa usia, jenis kelamin, status perkembangan, status kesehatan, sosiokultural, pelayanan kesehatan, sistem keluarga, pola hidup, lingkungan, dan ketersediaan sumber memengaruhi self care seseorang. Terkait hal tersebut peran petugas kesehatan dan peran keluarga sangat penting dalam perawatan diri penderita kusta.. Herawati (2019) dalam penelitiannya terdapat hubungan yang signifikan antara perawatan diri dengan cacat tingkat II di Kabupaten Cirebon.

Upaya yang dapat dilakukan untuk mencegah dampak buruk pada penderita kusta dengan cara peningkatan self care. Sehubungan dengan ini maka tujuan penelitian ini yaitu untuk mengetahui peran petugas kesehatan dan keluarga terhadap self care penderita kusta di Kecamatan Batuputih Kabupaten Sumenep. Kedua sistem ini sangat penting bagi penderita mengingat petugas kesehatan merupakan sumber daya untuk memberikan pelayanan kesehatan paripurna bagi masyarakat dan keluarga termasuk orang terdekat dengan klien. 


\section{Metode Penelitian}

Desain penelitian ini yaitu analitik dengan menggunakan rancang bangun Cross Sectional. Melakukan pengukuran/observasi data variabel independen dan dependen hanya satu kali pada satu waktu tanpa ada tindak lanjut. Populasi penelitian ini yaitu semua penderita kusta baik tipe kusta Pausy Bacillary (PB) maupun Multi Bacillary (MB) di Kecamatan Batuputih pada tahun 2020 sebanyak 35 responden. Sampel dalam penelitian ini merupakan kelompok kasus penderita kusta baik tipe kusta Pausy Bacillary (PB) maupun Multi Bacillary (MB) di Kecamatan Batuputih pada tahun 2020 sebanyak 25 responden. Teknik sampling menggunakan purposive sampling. Alat ukur dalam penelitian ini menggunakan lembar kuesioner dengan total pertanyaan sebanyak 33 pertanyaan valid dan reliabel dari variabel independen (peran petugas kesehatan dan peran keluarga) dan variabel dependen (self care). Teknik analisis data menggunakan uji korelasi spearmen.

\section{Hasil dan pembahasan}

1. Peran petugas kesehatan

Data hasil penelitian diperoleh sebagian besar petugas kesehatan berperan dalam perawatan penderita kusta sebanyak 16 orang.

Tabel 1 Distribusi frekuensi berdasarkan peran petugas kesehatan

\begin{tabular}{cccc}
\hline No & $\begin{array}{c}\text { Peran } \\
\text { Petugas }\end{array}$ & Frekuensi & \% \\
\hline 1 & Berperan & 16 & 64,0 \\
2 & $\begin{array}{c}\text { Tidak } \\
\text { Berperan }\end{array}$ & 9 & 36,0 \\
\hline Total & & 25 & 100 \\
\hline
\end{tabular}

Sumber: Data primer penelitian tahun 2020

Berdasarkan tabel 1 diperoleh distribusi responden berdasarkan peran petugas sebagian besar ikut berperan dalam self care penderita kusta sebanyak 16 orang $(64,0 \%)$ dan hampir setengahnya tidak berperan dalam self care penderita kusta sebanyak 9 orang (36,0\%).

Tabel 2 Korelasi Peran Petugas Kesehatan Terhadap Self Care Penderita Kusta

\begin{tabular}{lrrr}
\hline Variabel & $\begin{array}{c}\text { Korelasi } \\
\text { Koefisien }\end{array}$ & $\begin{array}{l}\text { Sig. (2- } \\
\text { tailed) }\end{array}$ & N \\
\hline $\begin{array}{l}\text { Peran } \\
\begin{array}{l}\text { Petugas } \\
\text { Kesehatan } \\
\text { Self Care }\end{array}\end{array}$ & 1,000 & & 25 \\
\hline \multicolumn{2}{l}{ Spearman's test Sig. $0,065(>0,05)$} \\
\hline
\end{tabular}

Sumber : Data Primer Penelitian Tahun 2020

Berdasarkan tabel 2 menyatakan bahwa tidak ada hubungan peran petugas kesehatan terhadap self care penderita kusta dengan hasil uji Spearman's test Sig. 0,065 (>0,05).

Ketersediaan fasilitas kesehatan, sikap, dan perilaku peran petugas kesehatan akan mendukung dan memperkuat terbentuknya perilaku. Peran petugas kesehatan merupakan komponen penting dalam pelaksanaan suatu pelayanan kesehatan. Oleh karena itu, keterampilan petugas kesehatan merupakan faktor pemungkin yang memengaruhi penderita kusta melakukan perawatan diri (Soagi, S.F, Arsin, A, Wahiduddin, 2014). Selain menyediakan fasilitas untuk perawatan, petugas juga mengajarkan bagaimana cara merawat diri untuk mencegah berlanjutnya cacat ke tingkat yang lebih berat. Beberapa peran petugas antara lain mengobati dan follow-up reksi kusta, dan memberikan pendidikan tentang perawatan luka kepada penderita (Mahanani N, 2013).

Penelitan yang dilakukan oleh Mahanani pada tahun (2013) kepada 39 responden penderita Kusta di puskesmas Kundur Kecamatan Kundur Kabupaten Blora sejalan dengan peneliti dimana sebagian besar petugas ikut berperan dalam perawatan penderita.

Peran petugas sangat berperan dalam proses penyembuhan kusta karena dengan adanya informasi-informasi yang mereka sampaikan akan sangat berpengaruh untuk menambah informasi mereka mengenai self care pada penderita kusta. Adanya penyuluhan yang sering mereka lakukan akan mempengaruhi pengetahuan masyarakat. Sehingga mereka akan memiliki pengetahuan mengenai self care bagi penderita kusta. Sehingga hal tersebut akan mempengaruhi penyembuhan kusta.

2. Peran keluarga

Data hasil penelitian diperoleh sebagian besar tidak berperan dalam self care penderita kusta sebanyak 15 orang.

Tabel 3 Distribusi frekuensi berdasarkan peran keluarga

\begin{tabular}{cccc}
\hline No & $\begin{array}{c}\text { Peran } \\
\text { Keluarga }\end{array}$ & Frekuensi & \% \\
\hline 1 & $\begin{array}{c}\text { Berperan } \\
\text { Tidak } \\
\text { Berperan }\end{array}$ & 10 & 40,0 \\
& 15 & 60,0 \\
\hline Total & 25 & 100 \\
\hline \multicolumn{3}{c}{ Sumber: Data primer penelitian tahun 2020 } \\
\multicolumn{3}{c}{ Berdasarkan tabel 3} & diperoleh \\
distribusi responden berdasarkan peran
\end{tabular}

57 | Journal Of Health Science 
keluarga hampir setengahnya ikut berperan dalam self care penderita kusta sebanyak 10 orang $(40,0 \%)$ dan sebagian besar tidak berperan dalam self care penderita kusta sebanyak 15 orang $(60,0 \%)$.

Tabel 4 Korelasi Peran Petugas Kesehatan Terhadap Self Care Penderita Kusta di Kecamatan Batuputih

\begin{tabular}{lrrr}
\hline Variabel & $\begin{array}{c}\text { Korelasi } \\
\text { Koefisien }\end{array}$ & $\begin{array}{l}\text { Sig. (2- } \\
\text { tailed) }\end{array}$ & N \\
\hline $\begin{array}{l}\text { Peran } \\
\text { Keluarga }\end{array}$ & 1,000 & $\cdot$ & 25 \\
Self Care &, 612 &, 001 & 25
\end{tabular}

Spearman's test Sig. $0,001(<0,05)$

Sumber : Data Primer Penelitian Tahun 2020

Berdasarkan tabel 4 menyatakan bahwa ada hubungan peran keluarga terhadap self care penderita kusta dengan hasil uji Spearman's test Sig. 0,001 $(<0,05)$.

Keluarga merupakan lingkungan sosial yang paling dekat dengan penderita. Proses penyembuhan dan pemulihan terjadi bukan hanya semata- mata karena faktor pelayanan kesehatan, tetapi juga faktor keluarga (Soagi, S.F, Arsin, A, Wahiduddin, 2014). Peran aktif keluarga dalam melakukan perawatan diri penderita kusta dapat mengurangi risiko penderita menjadi tuna sosial, tuna wisma, tuna karya dan cenderung melakukan kejahatan atau gangguan di lingkungan masyarakat (Mahanani N, 2013). Bantuan yang dapat diberikan oleh anggota keluarga adalah membantu mengerjakan pekerjaan penderita kusta yang berat dan berbahaya bagi tangan atau kaki yang mati rasa (Mahanani N, 2013).

Penelitian yang dilakukan oleh Mahanani pada tahun (2013) kepada 39 responden penderita Kusta di puskesmas Kundur Kecamatan Kundur Kabupaten Blora sejalan dengan peneliti dimana sebagian besar keluarga ikut berperan dalam perawatan.

Peran keluarga sangat diperlukan dalam melakukan self care sehingga hal tersebut akan mengurangi risiko penderita kusta. Dukungan keluarga sangat diperlukan untuk memberi dukungan pada yang sakit. Sehingga semangat mereka dalam melakukan self care dan semangat untuk sembuh juga tinggi untuk sembuh. Selain itu dukungan keluarga juga akan membangkitkan mental mereka untuk sembuh.

\section{Self care penderita kusta}

Data hasil penelitian diperoleh hampir seluruhnya self care penderita kusta dalam kategori kurang sebanyak 20 orang $(80,0 \%)$. Tabel 5 Distribusi frekuensi berdasarkan

\begin{tabular}{cccc}
\multicolumn{4}{c}{ self care } \\
\hline No & Self Care & Frekuensi & \% \\
\hline 1 & Baik & 5 & 20,0 \\
2 & Kurang & 20 & 80,0 \\
\hline Total & & 25 & 100 \\
\hline
\end{tabular}

Sumber : Data Primer Penelitian Tahun 2020

Berdasarkan tabel 5 diperoleh distribusi responden berdasarkan self care sebagian kecil dalam kategori baik sebanyak 5 orang $(20,0 \%)$ dan hampir seluruhnya dalam kategori kurang sebanyak 20 orang (80,0\%).

Orem mendefinisikan self care sebagai suatu yang harus dipelajari, kegiatan yang bertujuan membantu diri untuk mengelolah kehidupan yang di inginkan, kesehatan, perkembangan, dan kesejahteraan (Wahyuningsih A, Tavianda D, 2017). Pandangan teori Orem dalam tatanan pelayanan keperawatan ditunjukkan kepada kebutuhan individu dalam melakukan tindakan keperawatan ditunjukkan kepada kebutuhan individu dalam melakukan tindakan keperawatan mandiri serta mengatur dalam kebutuhanny (Wahyuningsih A, Tavianda D, 2017). Orem menggambarkan filosofi tentang keperawatan dengan cara seperti berikut (Wahyuningsih A, Tavianda D, 2017).

Penelitian yang dilakukan oleh Mahanani pada tahun (2013) kepada 39 responden penderita kusta di Puskesmas Kundur Kecamatan Kundur Kabupaten Blora sebagian besar penderita kusta atau responden melakukan self care.

Hasil penelitian ini sejalan dengan penelitian yang dilakukan oleh Nadhiro, dkk (2018) hasil analisis menunjukkan bahwa perawatan diri memiliki pengaruh terhadap distabilitas penyakit kusta secara langsung (Nadhiroh, Dharmawan, \& Murti, 2018).

Penelitian yang dilakukan oleh Pryce, dkk pada tahun 2018 pada penderita kusta di komunitas kusta yang ada kelompok di Nepal dari 53 peserta yang terkena kusta (100\%) adalah menyadari bahwa manajemen dapat membantu kondisi mereka, dengan mayoritas menyatakan beberapa dari empat direkomendasikan metode manajemen 52 menyatakan melindungi kaki mereka dengan alas kaki yang sesuai (98,1\%), 48 
berendam anggota badan mereka (90,6\%), dan 48 melakukan fisik latihan (90,6\%). Pentingnya memeriksa mata kurang dikenal, dengan hanya 22 peserta $(41,5 \%)$ menyatakan metode ini. Dari 53 peserta, 46 $(86,8 \%)$ menyadari setidaknya tiga dari empat ini metode dan 45 (84,9\%) berlatih setidaknya tiga metode. Jumlah rata-rata teknik yang diketahui oleh peserta dipengaruhi oleh LF adalah 1,81 $(\mathrm{SD}=0,951)$ dan jumlah rata-rata teknik yang dipraktikkan adalah 1,25 (SD = 1.404). Sebaliknya, jumlah rata-rata teknik diketahui oleh mereka yang terkena kusta adalah 3,21 $(\mathrm{SD}=0,717)(1,8 \mathrm{kali}$ lebih besar dari peserta yang terkena dampak LF) dan jumlah rata-rata teknik yang dipraktikkan adalah 3,08 $(\mathrm{SD}=0,703)(2,5$ kali lebih besar dari peserta dipengaruhi oleh LF). Baik pengetahuan dan praktik empat teknik perawatan diri utama untuk setiap kondisi berbeda secara signifikan (prycel, et al., 2018).

Self care yang baik dapat membantu proses penyembuhan pada penderita penyakit kusta. Self care yang berpengaruh besar adalah peran keluarga dan peran petugas karena semakin tinggi dukungan dari keluarga maka akan semakin tinggi juga semangat untuk sembuh dan peran petugas juga berpengaruh karena semakin sering mereka mendapatkan informasi mengenai self care maka akan semakin tinggi pula harapan untuk segera sembuh dari penyakitnya.

\section{Simpulan}

Sebagian besar petugas kesehatan berperan dalam self care penderita kusta, sedangkan keluarga sebagian besar tidak berperan dalam self care penderita kusta, dan hampir seluruhnya self care penderita kusta dalam kategori kurang. Maka dari itu, penelitian ini menyimpulkan bahwa tidak ada hubungan peran petugas kesehatan terhadap self care penderita kusta dan ada hubungan peran keluarga terhadap self care penderita kusta.

\section{Daftar Pustaka}

Alligood, M. R. (2014). NURSING THEORISTIST AND THEIR WORK. Dalam M. R. Alligood, NURSING THEORISTIST AND THEIR WORK, EIGHTH EDITION (hal. 240-257). St. Louis: Mosby.

Amiruddin. (2019). Penyakit Kusta "Sebuah Pendekatan Klinis". Surabaya: Brilian Internasional.
Badan Pusat Statistik. (2018). Indikator Tujuan Pembangunan Berkelanjutan (TPB) Indonesia 2018. Jakarta: BPS-Statistics Indonesia.

Dinas Kesehatan Kabupaten Sumenep. (2020). Situasi Penyakit Kusta Kabupaten Sumenep Tahun 2019 (31 Desember 2019). Sumenep: Dinas Kesehatan Kabupaten Sumenep.

Dinas Kesehatan Provinsi Jawa Timur. (2020). Umpan Balik Kegiatan Program Pemberantasan Penyakit Kusta Tahun 2019 Per Kabupaten/Kota. Surabaya: Dinas Kesehatan Provinsi Jawa Timur.

Eldiansyah F, Wantia, Siswoyo. (2016). Perbedaan Tingkat Kecacatan Klien Kusta Yang Aktif dan Tidak Aktif Mengikuti Kegiatan Kelompok Perawatan Diri (KPD) di Kabupaten Jember. 286-292.

Infodatin. (2018). Hapuskan Stigma Dan Diskriminasi Terhadap Kusta. Jakarta: Kementrian Kesehatan RI.

Mahanani N. (2013). Fakto-Faktor yang berhubungan dengan perawatan diri kusta pada penderita kusta di puskesmas kunduran kecamatan kunduran kabupaten blora tahun 2011. 1-66.

Nadhiroh, U., Dharmawan, R., \& Murti, B. (2018). Determinans of Disability in Patients with Leprosy at Kelet Hospital, Central Java. Journal of Epidemiology and Public Health, 143152.

Nunzi, E., \& Massone, C. (2012). Leprosy A Practical Guide. Italia: SpringerVerlag.

Nursalam. (2016). Metodologi Penelitian Ilmu Keperawatan "Pendekatan Praktis". Jakarta: Salemba Medika.

Permenkes. (2019). Peraturan Menteri Kesehatan Republik Indonesia Nomor 11 Tahun 2019 Tentag Penanggulangan Kusta. Jakarta: Menteri Kesehatan Republik Indonesia.

Prycel, j., mableson, h. E., choudhary, r., pandey, b. d., aley, d., betts, h., et al. (2018). Assessing the feasibility of integration of self-care for filarial lymphoedema into existing 
community leprosy self-help groups in Nepal. BMC Public Health, 1-13.

Soagi, S.F, Arsin, A, Wahiduddin. (2014). faktor yang berhubungan dengan perawatan diri pada penderita kusta di RS Dr. tadjuddin chalid makasar. 6.

Sutopo, A., Arthati, D. F., \& Rahmi, U. A. (2014). Kajian Indikator Lintas Sektor "Kajian Indikator Sustainable Development Goals (SDGs). Jakarta: Badan Pusat Statistik.

Wahyuningsih A, Tavianda D. (2017). Mengukur self care pada pasien diabetes mellitus tipe II. Nganjuk: Abjie media nusantara. 